\title{
Assessment of Physico-chemical Characteristics, Viability and Inhibitory Effect of Bifidobacteria in Soymilk
}

\author{
S. O. Ebhodaghe, S. H. Abiose \& H. A. Adeniran (Corresponding author)
}

Department of Food Science and Technology

Obafemi Awolowo University, Ile-Ife, Nigeria

Tel: 234-803-470-7033_E-mail: ahezekiahadeniran@yahoo.com, hadeniran@oauife.edu.ng

$\begin{array}{lr}\text { Received: February 27, } 2012 \quad \text { Accepted: March 14, } 2012 \quad \text { Published: May 1, } 2012 \\ \text { doi:10.5539/jfr.v1n2p159 } & \text { URL: http://dx.doi.org/10.5539/jfr.v1n2p159 }\end{array}$

\begin{abstract}
The study investigated viability of Bifidobacteria isolates from breast-fed infants in soymilk with the aim of producing a beverage with health- improving potentials from an affordable source.

Strains of Bifidobacteria spp isolated from breast-fed babies were identified on the basis of morphological and biochemical characteristics. The pure isolates were inoculated into sterile soymilk and their viability was studied at ambient $\left(28 \pm 2{ }^{\circ} \mathrm{C}\right)$ and refrigeration temperatures $\left(4 \pm 1^{\circ} \mathrm{C}\right)$ The bifidobacteria isolates were identified as $B$. adolescentis and Bifidobacterium longum. The inhibitory effects of the Bifidobacteria isolates were tested on Escherichia coli and Staphylococcus aureus. B. longum was found to be viable for 35 days and inhibited Escherichia coli better than Staphylococcus aureus. Changes in the physico-chemical characteristics of the inoculated soymilk were also monitored over the storage period.
\end{abstract}

Crude protein increased from 1.76 to $2.14 \%$ and $1.96 \%$ in soymilk samples stored at ambient and refrigeration temperatures respectively.

The study has shown that B. longum which is supported by soymilk exhibits antimicrobial activity against tested food borne pathogens - indicating that probiotic soymilk could be produced from B. longum and soymilk.

Keywords: Ambient, Refrigeration, Bifidobacterium, Inhibitory, Soymilk, Viability

\section{Introduction}

Probiotics are live microorganisms which when ingested enhance the well-being of the host through their effects on the intestinal microflora (Havenaar \& Veld, 1992; Aunty et al., 2001). Other reported positive effects of probiotics include digestion of lactose, synthesis of vitamins and lowering of serum cholesterol levels (Aramide $e t$ al., 2009). They contribute to biological defense mechanisms, prevention of diseases, recovery from diseases, and control of physical conditions and influence the ageing process (Patidar \& Prajapati, 1997). From the foregoing, incorporation of probiotic bacteria with scientifically supported health claims in foods has great potentials for improving the quality of life.

The most widely used probiotics belong to the genera Lactobacillus and Bifidobacterium (Bowley, 2005). Bifidobacterium is the dominant bacteria in the intestinal microflora of breast-fed infants (Abe, 2004). For a probiotic bacteria to benefit human health it must be able to withstand the manufacturing process without losing its viability and functionality when incorporated into food products (Saarela et al., 2000). Dairy products have been employed in the food industry and embraced by many consumers as vehicle of delivering probiotic microorganisms. Various types of fermented milk products including bifidus milk, and bifidus-acidophilus milk are examples of popular probioticated products obtained with Bifidobacteria (Kurman \& Rasic, 1993; Patidar \& Prajapati, 1997).

Currently, efforts are being made to use plant sources such as roselle extract, ginger and garlic extract as substrates for cultivating probiotics (Aramide et al., 2009, Adeniran et al., 2010). Soy products have been suggested as the best substitute for dairy products (Tsangali et al., 2002). Among the reasons for this are low cost, being lactose-free, non-allergenecity and low technology required. It is reported that soymilk can be produced for about one third to one half the cost of cow's milk and a unit area of the land can produce about 10 times as much soymilk per year as dairy milk (Samona, 1993). Thus it is important that the developing countries begin to think of partially 
replacing the increasingly expensive dairy products with high quality soymilk (Nsofor \& Osuji, 1997). In addition, lactose intolerant people feel discomfort and pain, usually accompanied by diarrhea when they consume dairy milk (Poskitt, 1993). Soymilk can be consumed by these groups of people since it contains no lactose and has been reported to be an excellent dairy milk substitute (Nsofor \& Osuji, 1997; Omoni \& Aluko, 2005).

Furthermore, the other documented health advantage of consuming soymilk is its being cardio protective. That is, it contains beneficial cholesterol, not the bad cholesterol that can cause thrombosis and high blood pressure. A diet high in soy foods has been associated with reduced risk of several types of cancer, such as breast, endometrial and prostate. Soy isoflavones' antioxidant properties likely contribute to soy foods' anti-cancer effects by reducing free radical damage to fats (lipid peroxidation) and DNA. Soy isoflavones may also induce Phase II liver enzymes (such as glutathione-s-transferase and quinone reductase), which help the body eliminate the toxic byproducts (aromatic hydrocarbons) produced when meats are charbroiled (Azadbakht et al., 2003). Soymilk has also been found to be capable of reducing Type 2 diabetes, kidney and health diseases (Villegas et al., 2008)

This study therefore examined the viability of Bifidobacteria species isolated from breast-fed babies in soymilk for five weeks. The isolates were earlier characterized and their inhibitory effects on potentially pathogenic organisms in soymilk evaluated. Accompanying changes in physic-chemical characteristics of the inoculated soymilk were also monitored over a period of storage.

\section{Materials and Methods}

Soybeans were purchased from the main market, Ile-Ife, Nigeria. The pathogenic organisms, Escherichia coli (type strain NCIB 86) and Staphylococcus aureus (type strain NCIB 8588) used were obtained from the Department of Microbiology, Obafemi Awolowo University, Ile-Ife, Nigeria.

\subsection{Methods}

The experiment included isolation of Bifidobacteria and Lactobacilli spp from faecal samples from breast-fed babies, characterization of the microbes, preparation of soymilk, inoculation of the milk with the bacterial isolates and determination of inhibitory effect of probiotic microbe with pathogenic organisms.

\subsection{Preparation of soymilk}

Soybeans were processed into milk using the method shown in flow chart of Figure 1. Subsequently, $27 \mathrm{ml}$ of the prepared soymilk was dispensed into $30 \mathrm{ml}$ screw capped test tubes and heat treated in an autoclave at $115^{\circ} \mathrm{C}$ for 20 mins.

\subsection{Microbiological analyses}

Media for cultivation, isolation and identification of bacterial isolates were of analytical grade (Oxoid, England); and were prepared using standard methods. All media for bacteria cultivation and identification were sterilized by autoclaving at $121{ }^{\circ} \mathrm{C}$ for 15 mins.

\subsubsection{Isolation of Bifidobacterium and lactobacillus species from faecal samples}

Faecal samples (20 samples) from healthy breast fed babies were collected from the Children's immunization section of the Obafemi Awolowo University, Teaching Hospital complex, IleIfe, Nigeria into sterile McCartney bottles and immediately transported to the laboratory.

Isolation of Bifidobacteria was done by mixing one gram of each of the faecal samples with $9 \mathrm{ml}$ of reinforced clostridial medium (a diluent for anaerobes) (Harrigan \& McCance, 1976; Harrigan, 1998). Serial dilutions were done and pour plates were made with a selective medium, trypticase peptone yeast extract agar (TYP) supplemented with $0.1 \%$ sodium thioglycholate and $0.5 \%$ propionic acid (Olutiola et al., 1991; Yusof et al., 2000). Plates were incubated at $37^{\circ} \mathrm{C}$ for $72 \mathrm{~h}$ under anaerobic condition using anaerobic jar and gas generating kit (Oxoid; Basing stoke, U.K). From the diluted samples, Lactobacilli were isolated by mixing $1 \mathrm{ml}$ of samples with de Man Rogosa and Sharpe agar, (MRS) containing $1 \%$ Sodium azide. The $1 \%$ sodium azide provided micro aerophilic condition (Harrigan \& McCance, 1976; Brankovi \& Baras, 2001). Plates were incubated at $37{ }^{\circ} \mathrm{C}$ for $72 h$ under aerobic conditions.

\subsubsection{Identification of bacterial isolates}

Representative colonies on trypticase peptone yeast extract agar and de Man Rogosa and Sharpe agar were picked on the basis of their cultural characteristics, and purified by repeated streaking on the fresh sterile media plates and incubated. Pure cultures obtained were coded and transferred to agar stabs and slants respectively and stored in the refrigerator until required for identification. The bacteria isolates were identified based on their cultural, morphological and biochemical characteristics following the schemes of Harrigan and McCance (1976) and 
Sgorbati et al. (1995). Characterization was based on cultural and microscopic morphology, Gram's reaction, growth characteristics, and selected biochemical tests including catalase test, nitrate reduction, ammonia reduction, and sugar fermentation test.

\subsubsection{Preparation of test samples for inoculation}

(a) Prepared sterile soymilk (27ml) was dispensed into each of the test tubes and each tube was inoculated with $3 \mathrm{ml}$ of pure Bifidobacteria culture at $10 \%(\mathrm{v} / \mathrm{v})$ concentration. A set of the samples was stored at ambient temperature $\left(28 \pm 2{ }^{\circ} \mathrm{C}\right)$ while the other set was refrigerated $\left(4 \pm 1{ }^{\circ} \mathrm{C}\right)$ for viability test.

(b) For the antagonism test, equal number of tubes containing $28 \mathrm{ml}$ of sterile soymilk was each inoculated with $1 \mathrm{ml}$ of the Bifidobacteria culture and $1 \mathrm{ml}$ of $24 h$ old culture of $E$. coli. The test samples were stored at ambient temperature.

(c) Another set of tubes containing $28 \mathrm{ml}$ of sterile soymilk were each inoculated with $1 \mathrm{ml}$ of the Bifidobacteria culture and $1 \mathrm{ml}$ of $24 \mathrm{~h}$ old culture of Staphylococcus aureus. Samples were kept at ambient temperature.

(d) Equal number of tubes as in ( $\mathrm{b}$ and c) above containing the sterile soymilk was each inoculated with $1 \mathrm{ml} 24 \mathrm{~h}$ old culture of $E$. coli. This served as control samples for the test samples in (b) above. The control samples were also stored at ambient temperature.

(e) The same number of tubes with each containing $28 \mathrm{ml}$ of sterile soymilk as in (d) above was each inoculated with $1 \mathrm{ml}$ of $24 \mathrm{~h}$ culture of Staphylococcus aureus. This served as control for (d) above. Samples were kept at ambient temperature.

\subsubsection{Determination of the viability of Bifidobacteria isolates in soymilk}

Counts of the Bifidobacteria were determined weekly for 5 weeks from inoculated soymilk samples stored at both ambient and refrigeration temperatures. From each tube, $1 \mathrm{ml}$ was pipetted into $9 \mathrm{ml}$ of reinforced clostridial medium, mixed thoroughly and serial dilutions of the mixture were made and the microbe enumerated using pour plate method. Diluted samples were poured trypticase peptone yeast extract agar supplemented with $0.1 \%$ ascorbic acid and $0.5 \%$ propionic acid (Hoover, 1999). The plates were incubated at $37{ }^{\circ} \mathrm{C}$ under anaerobic condition for $72 \mathrm{~h}$ and the colony count of the Bifidobacteria colonies was done using a Gallenkamp colony counter (CNW-300 model) (Harrigan \& McCance, 1976; Harrigan, 1998)

2.3.5 BIn vitro antagonism of Bifidobacteria isolates and pathogenic strains in soymilk

The inhibiting effect of the selected Bifidobacteria species on food borne bacterial pathogens was assayed by the broth culture method described by Visser \& Holzapfel (1992) and Kobayashi et al., (2003). Samples were taken from each test tube of soymilk inoculated with $1 \mathrm{ml}$ of Bifidobacteria culture and $1 \mathrm{ml}$ each of $24 h$ cultures of $E$. coli and $S$. aureus respectively, and from each tube of the soymilk samples inoculated with $1 \mathrm{ml}$ each of the pure cultures of the pathogenic organisms all stored on the shelf at room temperature, weekly for 5 weeks for counts of the pathogens.

\subsubsection{Escherichia coli}

Counts for E. coli was accomplished by mixing $1 \mathrm{ml}$ of the soymilk (containing Bifidobacteria culture and $1 \mathrm{ml}$ each of $24 h$ cultures of $E$. coli) into $9 \mathrm{ml}$ of $0.1 \%$ peptone water diluent (Harrigan \& McCance, 1976) and mixed thoroughly. Serial dilution of each of the inoculated samples was carried out. From each diluted sample, $1 \mathrm{ml}$ was pipetted into each plate and about $20 \mathrm{ml}$ of MacConkey agar was introduced into each (Harrigan and McCance, 1976; Olutiola et al., 1991). The plates were incubated aerobically at $37{ }^{\circ} \mathrm{C}$ and observed after $24 h$ (Yusof et al., 2000). Counts were achieved using a Gallenkamp colony counter (CNW-300 model).

\subsubsection{Staphylococcus aureus}

Counts of $S$. aureus was achieved by mixing $1 \mathrm{ml}$ of the sample (containing Bifidobacteria culture and $1 \mathrm{ml}$ each of $24 \mathrm{~h}$ cultures of $S$. aureus overnight culture of $S$. aureus into $9 \mathrm{ml}$ of a $0.1 \%$ peptone water diluent (Harrigan and McCance, 1976; Harrigan, 1998) and mixed thoroughly. Serial dilution of the inoculated samples was carried out and pour plates made with Mannitol Salt agar. The plates were incubated aerobically at $37^{\circ} \mathrm{C}$ and observed after 24h. Counts were done using a Gallenkamp colony counter (CNW-300 model).

\subsection{Determination}

\subsection{1 $\mathrm{pH}$, Titratable acidity and total solids determination}

The method of AOAC (2000) was employed in determination of $\mathrm{pH}$, Titratable acidity (TTA) and Total Solids 


\subsubsection{Determination of Amino Nitrogen}

Amino nitrogen was determined using the Formol titration method (Frais, 1972). The formaldehyde used in this analysis was first neutralized with standardized $0.1 \mathrm{M}$ sodium hydroxide solution. Five ml of each soymilk sample were put in conical flasks and two to three drops phenolphthalein added. These were then neutralized with standardized $0.1 \mathrm{M}$ sodium hydroxide solution, adding the alkali dropwise until the faintest permanent pink color was produced. Six milliliters of the neutralized formaldehyde solution were added to each of the neutralized soymilk samples. The disappearance of the pink color was observed, and then the contents of the flasks were titrated against the standard sodium hydroxide solution until a pink colour was produced as before, the titre values were recorded and used in calculating the amino nitrogen present in each sample.

\subsubsection{Determination of total reducing sugar.}

Total reducing sugar was determined by the use of Dinitrosalicylic reagent (Miller, 1959 \& Adeniran et al., 2008). The soymilk samples were diluted to 4 times its volume with distilled water and filtered through a paper filter placed in a funnel. One $\mathrm{ml}$ of each of the sample's filtrate was put in test tubes and $1 \mathrm{ml}$ distilled water was put in another test tube as blank after which $1 \mathrm{ml}$ of DNSA was added to each of the test tubes and boiled for 5mins. After boiling, $10 \mathrm{mls}$ of distilled water were added to each tube and the absorbance read at $540 \mathrm{~nm}$ in a Spectrophotometer (CECIL CE 3041 model). The reducing sugar concentrations of the samples were read from a calibration curve prepared by measuring the absorbance of varying concentrations of glucose and DNSA reagent at $540 \mathrm{~nm}$.

\subsubsection{Determination of Proximate Composition of inoculated soymilk}

AOAC (2000) method was used to determine the proximate composition of the soymilk after inoculation with $B$. longum and during subsequent storage at ambient and refrigerated temperatures.

\subsection{Statistical analysis}

The values obtained from each of the analyses were means of triplicate readings. Origin Pro (1999-20020) computer package was employed to analyze the experimental data generated.

\section{Results and Discussion}

\subsection{Identification of human intestinal probiotic strains}

Strains of Bifidobacteria isolated from fecal samples of breast fed babies were characterized as shown in Table 1 . They were identified on the basis of their unique morphology of V- or Y-shape or being multiple branched rods. This is an important differentiating property between the two related genera Bifidobacterium and Lactobacillus as (Mitsuoka, 1992; Sgorbati et al., 1995; Brankovi \& Baras, 2001). The bifidobacteria isolates were identified as Bifidobacterium longum and Bifidobacterium adolescentis based on their fermentation characteristics. Both species have been reported to be a part of the faecal bacteria population in breast fed babies (Mitsuoka, 1992; Sgorbati et al., 1995). Most of the Bifidobacteria isolates in this study were identified as Bifidobacterium longum. It is considered the commonest species of Bifidobacteria found both in infant and adult faecal material (Sgorbati et al., 1995).

The DNA of B. longum is said to be $50-76 \%$ related to that of Bifidobacterium infantis. This close genetic relationship is reflected in their similar fermentation activity (Sgorbati et al., 1995) and the identification of strains belonging to one of the two species is reported to remain a difficult task (Sgorbati et al., 1995). For identification, Scardovi (1986) suggested that strains able to ferment arabinose and melezitose be regarded as $B$. longum while strains that cannot ferment arabinose be held as $B$. infantis.

The Lactobacillus strains isolated were characterized on basis of their morphology and fermentation profile as Lactobacillus fermentum, Lactobacillus plantarum and Lactobacillus salivarius (Mitsuoka, 1992).

\subsection{Viability of the Bifidobacteria isolates in soymilk.}

Bifidobacterium longum, which was inoculated into the sterile soymilk, proliferated in soymilk as shown in Figure 2. An initial increase in population was observed in samples stored at both storage temperatures; this was followed by a decrease from the 21 st day onward. This observation agrees with the finding of Gilliland et al. (2002) in which the growth of $B$. longum was monitored in a fermented milk product over a period of 35 days. This decrease after 21 days could be explained as being the result of diminishing nutrient supply (Tsangalis et al., 2002) and decreasing $\mathrm{pH}$ below values required for optimum growth (Hoover, 1999). Aramide et al., (2009) found Lactobacillus acidophilus and L. plantarum viable in roselle extract after 27 days of storage at ambient temperature while Adeniran et al., (2010) also reported that after 5 weeks of storage of inoculated samples at 
ambient temperature, L. bulgaricus and L. plantarum were still viable in ginger extract. Finding of the present study is in agreement with similar studies on Lactobacillus spp on plant-based beverages.

The rate of population reduction was lower in the refrigerated samples as expected. A slight decrease in bacteria population during the first seven days of refrigeration was also observed. This could be due to the sudden cold storage (Hoover, 1999; Prescott et al., 1999, Adeniran et al., 2010) or cold shock effects on the microbial cells, a phenomenon called the lag phase. This also accounted for the lower Bifidobacteria counts observed when compared to samples stored at room temperature especially at periods of maximum microbial growth, day 14 and 21. Generally, the growth of microorganisms and in particular Bifidobacteria is known to slow down at low temperatures (Hoover, 1999; Gilliland et al., 2002).

The higher counts in the refrigerated samples on the 28th and 35th day could be as a result of residual nutrients in the soymilk which was being slowly used up by the growing microbial population and also as the result of the slightly higher $\mathrm{pH}$ values which were within the $\mathrm{pH}$ values for the optimum growth of Bifidobacteria (Hoover, 1999; Gilliland et al., 2002). The values were further subjected to statistical analysis and the correlation between storage at room and refrigeration temperatures were found not to be statistically significant at $5 \%$ level. This suggests that the soymilk probioticated with $B$. longum could be stored at both temperatures without significant reduction in the bacterial counts.

B. adolescentis, on the other hand, was observed to be viable in the inoculated soymilk for less than 3 days at ambient and refrigeration temperatures. No viable count of the isolate was recorded at $3^{\text {rd }}$ day of incubation in the soymilk samples. The reason for the non-proliferation of this organism in soymilk could be due to its inability to metabolize the predominant sugars in the soymilk, which were mainly raffinose and stachyose requiring $\alpha$-galactosidase activity for metabolism (Hoover, 1999; Tsangalis et al., 2002). Also, this particular isolate was found to be a strict anaerobe. This could have caused its non-proliferation in the soymilk since steps were not taken to ensure a low oxidation - reduction potential in the medium during storage (Hoover, 1999; Gilliland et al., 2002).

\subsection{Antimicrobial effect of the isolate Bifidobacterium longu}

Presented in Figure 3 is the result of viable counts of food borne pathogens which were cultured with B. longum in soymilk, stored at ambient temperature. This is the temperature at which pathogens grow and produce toxins (Prescott et al., 1999). This result reflects the inhibitory effects of the test probiotic strain against food borne pathogens E. coli and S. aureus. According to earlier findings, Bifidobacteria have been known to help in maintaining healthy functioning of the intestinal tract directly through antimicrobial activity (Danone, 1997). The results obtained in this study show that the pathogens E. coli and S. aureus had higher counts when grown as pure cultures in the soymilk than when grown in combination with the probiotic isolate, throughout the duration of storage. This is in agreement with the results of a study which showed a reduction, and finally the extinction of a plant pathogen treated with the probiotic strain L. plantarum (Visser \& Holzapfel, 1992).

Figure 3 also shows that the growth of E.coli was better inhibited compared to the growth of S. aureus. Escherichia coli has been reported to be strongly inhibited by acetic acid, especially by those produced by some strains of the probiotic species B. longum (Kobayashi et al., 2003; Ibrahim et al., 2005) and could be inferred that the inhibitory effect on E.coli observed in Figure 3 could be due to the presence of organic acid (likely acetic acid) produced by the probiotic strain in the soymilk. As with other short chain fatty acids the undissociated form of the molecule acetic acid mediates the antimicrobial effect by collapsing the electrochemical proton gradient causing bacteriostasis and eventual death of susceptible bacteria. Acetic acid and propionic acid have higher pKa values than lactic acid and therefore a higher undissociated ratio at a given $\mathrm{pH}$. This is reported to be one reason for their increased antimicrobial efficacy compared to lactic acid (Earnshaw, 1992).

For sample containing the probiotic strain and the pathogen $S$. aureus, the degree of inhibition by the probiotic strain was observed to be lower and the pathogen remained viable throughout storage duration while for the sample containing the probiotic strain and the pathogen E. coli, the pathogen remained viable until the 21st day of storage when it was completely inhibited. Findings of Bowley (2005); Ibrahim et al. (2005); Aramide et al. (2009) and Adeniran et al. (2010) affirmed that different probiotic strains exhibit different degree of inhibition against different types of pathogens.

\section{$3.4 \mathrm{pH}$ and titratable acidity values of B. longum inoculated soymilk}

From Table 2, it can be seen that the $\mathrm{pH}$ values of samples stored at ambient temperature showed a decrease from 5.72 on the first day of storage to $\mathrm{pH} 4.58$ on the 7 th day compared to refrigerated samples which showed a gradual decrease from 5.72 on the first day of storage to 5.63 on the 7th day. At the end of storage period, the $\mathrm{pH}$ was 4.36 and 5.35 respectively for samples stored at ambient and refrigeration temperatures. There was no appreciable 
change in the $\mathrm{pH}$ of the control samples by the 35th day. The decrease in $\mathrm{pH}$ of the test samples was probably due to the production of short chain carboxylic acid such as acetic acid and lactic acid, the major fermentation products of the genus Bifidobacterium (Yusof et al., 2000; Kobayashi et al., 2001; Brankovi \& Baras, 2001; Tsangalis et al., 2002). The difference in the rate of decrease in the $\mathrm{pH}$ of samples stored at ambient temperature compared to those refrigerated was due to relatively higher level of microbial growth and hence increased acid production (Prescott et al., 1999). The $\mathrm{pH}$ was not low enough to cause a permanent change in the consistency of the soymilk by the end of the storage period.

Result of TTA indicates that that the acidity of the inoculated samples increased with storage time.

\subsection{Total solid content}

The total solids decreased from 5.16 to $4.43 \%$ at the end of the storage period for samples stored at ambient temperature and from 5.16 to 4.50 for samples stored at refrigeration temperature (Table 2). This could be attributed to the uptake of these solids by the growing microbial population (Nsofor et al., 1997; Rani \& Khetarpaul, 1999).

\subsection{Amino Nitrogen and crude protein content}

Table 3 shows the changes in amino nitrogen and crude protein content of soymilk samples inoculated with $B$. longum stored at ambient and refrigeration temperatures. An initial increase of the amino nitrogen content was observed from 0.18 to $0.22 \mathrm{mg} \mathrm{ml}^{-1}$ in the two sets of probioticated soymilk samples. This could be due to partial breakdown of protein to peptide and amino acid (Rani \& Khetarpaul, 1999). Thereafter, the amino nitrogen level was observed to be quite stable. It is likely that the amino nitrogen taken up by the multiplying $B$. longum population was being replaced via autolysis of some of the microbial cells in the soymilk. Since nitrogen is required for growth and biosynthesis of components of the bacterial cells, inadequate quantity and poor quality of free amino acids could activate bacterial proteolytic enzymes so that the amino acids might increase as a result of hydrolysis of the milk substrate (Brankovi \& Baras, 2001). One of the beneficial effects of Bifidobacteria is the preservation of nitrogen content by preventing putrefaction thus it has been reported that the adaptation of Bifidobacterium species to gastrointestinal tract enhances nitrogen retention (Gibson et al., 1997).

The crude protein content for samples stored at ambient temperature also increased gradually from 1.76 to $2.14 \%$ and from 1.76 to $1.96 \%$ for samples stored at refrigeration temperature (Table 3 ). This could have been caused by increase in the production of proteins from the multiplication of microbial cells, which are mainly proteins. Amino nitrogen and crude protein were not significantly different at ambient and refrigeration temperatures of storage $(\mathrm{p}>$ $0.05)$.

\subsection{Total reducing sugar and carbohydrate content}

The total reducing sugar content of the test samples (Table 3) showed an increase by the slowly multiplying Bifidobacteria population in the samples from 1.28 to $3.77 \%$ for samples stored at ambient temperature and from 1.28 to $2.49 \%$ for samples stored at refrigeration temperature by the 7 th day of storage. This increase in reducing sugar content of the test samples was possibly due to the production of reducing sugars via hydrolysis of the predominant $\alpha$ - galactosyl oligosaccharides including raffinose and stachyose present in the soymilk (Tsangalis $e t$ al., 2002). These sugars have been found to be satisfactory fermentable substrate for the growth of bifidobacteria in soymilk (Garro et al., 1999; Tsangalis et al., 2002). This is because it has been shown from experimental studies that Bifidobacterium species produce intracellular $\alpha$-galactosidase required to metabolize these sugars (Tsangalis et al., 2002). The subsequent reduction in the sugar content of the test samples is suggested to be due to its utilization (Garro et al., 1999; Brankori \& Baras, 2001). The slightly higher values observed in the refrigerated test samples were due to slower utilization.

The initial sharp reduction in carbohydrate values observed between the $1^{\text {st }}$ and the $7^{\text {th }}$ day of storage from 3.75 to $1.67 \%$ for samples stored at ambient temperature could be related to hydrolysis of the carbohydrate by amylolytic enzymes of the probiotic bacteria resulting in the increased reducing sugar production observed during the same period (Rani \& Khetarpaul, 1999; Tsangalis et al., 2002) and thus starch digestibility.

\section{Conclusion}

It can be concluded that of the two Bifidobacteria species isolated from breast-fed babies, B. longum was found to proliferate in soymilk for 35 days. Also, the microbe exhibited antimicrobial activity against $E$. coli and $S$. aureus though to a greater degree in the former than the latter. In addition, soymilk which supported the potentially probiotic $B$. longum, has also been shown to have great potentials in the formulation of probiotic beverages. 


\section{References}

Abe., F. (2004). Bifidobacteria Promote Infant Health. Journal of Food Technology International, 1, 36 - 37.

Adeniran, H. A., Abiose, S. H., \& Ogunsua, A. O. (2008). Production of Fungal $\exists$ - amylase and Amyloglucosidase on some Nigerian Agricultural Residues. Food Bioprocess Technology, 3(5), 693-698. http://dx.doi.org/10.1007/s11947-008-0141-3

Adeniran, H. A., Abiose, S. H., \& Ukeyima, M. T. (2010). Microbiological Assessment of probioticated ginger-based beverages. Nutrition and Food Science, 40(2), 209-220. http://dx.doi.org/10.1108/00346651011029246

Aramide, A. A., Abiose, S. H., \& Adeniran, H. A. (2009). Microbial Evaluation of Probiotic Beverage from Roselle extract. African Journal of Food Science, 1(12), 385-392.

Auty, M. A. E., Gardiner, G. E., Mc Brearty, S. J., O’sullivan, E. O., Mulvihill, D. M., Collins, J. K., Fitzgerald, G. F., Stanton, C., \& Ross, R. P. (2001). Direct In Situ Viability Assessment of Bacteria in Probiotic Dairy Products Using Viability Staining in Conjunction with Confocal Scanning Laser Microscopy. Journal of Applied and Environmental Microbiology, 67(1) 420-425. http://dx.doi.org/10.1128/AEM.67.1.420-425.2001

Azadbakht, L., Shakerhosseini, R., Atabak, S., Jamshidian, M., Mehrabi, Y., \& Esmaill-Zadeh, A. (2003). Beneficiary effect of dietary soy protein on lowering plasma levels of lipid and improving kidney function in type II diabetes with nephropathy. European Journal of Clinical Nutrition, 57(10), 1292-1294. http://dx.doi.org/10.1038/sj.ejen.1601688

Bowley, A. (2005). Probiotics. Nutriview, 1, 8.

Brankovi, S. D., \& Baras, J. (2001). Comparative Study on Biochemical Activity of the Intestinal Isolates Lactobacillus Species V3 and Bifidobacterium species A71 in Different Substrates. Journal of Serbian Chemical Society, 66(9), 581-589.

Danone. (1997) Bifidobacteria. Danone World Newsletter, 16.

Earnshaw, R. G. (1992). Antimicrobial Action of Lactic Acid Bacteria: Natural Food Preservation Systems. In B. J. B. Wood (Ed.), The Lactic Acid Bacteria. Voll. London: Elsevier Science Publishers. http://dx.doi.org/10.1007/978-1-4615-3522-5_9

Frais, F. (1972). Introductory Biochemistry: An Introductory Course. London: Butterworth and Co Ltd. Pub.

Garro, M. S., Valdez, G. F., de Oliver, G., \& Giori, G. S. de. (1999). Hydrolysis of soymilk oligosaccharides by Bifidobacterium longum CRL849. Food Research and Technology, 208 (1), 57 -59.

Gibson, G. R., Saavedra, J. M., Macfarlane, S., \& Macfarlane, G. T. (1999). Probiotics and Intestinal infections. In R. Fuller (Ed.), Probiotics 2: Applications and Practical Aspects. London: Chapman and Hall.

Gilliland, S. E., Reilly, S. S., Kim, G. B., \& Kim, H. S. (2002). Viability during storage of selected Probiotic Lactobacilli and Bifidobacteria in Yoghurt- like Product. Journal of Food Science, 67 (8), 3091-3095. http://dx.doi.org/10.1111/j.1365-2621.2002.tb08864.x

Harrigan, W. F., \& McCance, M. E. (1976). Laboratory Methods in Food and Dairy Microbiology. London: Academic Press Publishers.

Harrigan, W. F. (1998). Laboratory Methods in Food Microbiology (pp 155-230). San Diego: Academic Press.

Havenaar, R., \& Veld, J. H. J. (1992). Probiotics: A General view, In B.J.B. Wood (Ed), The Lactic Acid Bacteria, Vol. 1. London: Elsevier Science Publishers.

Hoover, G. (1999) Bifidobacterium In Encyclopedia of Food Microbiology, Vol 1, (pp 210-212). London : Academic Press. http://dx.doi.org/10.1006/rwfm.1999.0170

I. I. T. A. (1989). Soybeans for Good Health: How to Grow and Use Soybeans in Nigeria International Institute for Tropical Agriculture, Ibadan, Nigeria.

Ibrahim, S. A., Dharmavaram, S. R., Seo, C. W., \& Shahbazi, G. (2005) Antimicrobial activity of Bifidobacterium longum (NCFB 2259) as influenced by Spices. Internet Journal of Food Safety, 2, 6-8.

Kobayashi, I., Muraoka, H., Saika, T., Nishida, M., Akita, H., Iwata, S., Sato, Y., \& Sunakawa, K. (2003). Inhibitory Effect of Bifidobacteria on the In vitro Production of Verotoxins by Escherichia coli 0157:H7. Japan Bifidus Foundation, 81-84. 
Kurmann, J. A., \& Rasic, J. L. (1993). Bifidobacteria in Foods. In Encyclopedia of Food Science, Food Technology and Nutrition Vol. 1, (pp 374-378). London: Academic Press.

Miller, G. L. (1959). Use of dinitrosalicylic acid reagent for determination of reducing sugar. Analytical Chemistry, 31, 426-428. http://dx.doi.org/10.1021/ac60147a030

Mitsuoka, T. (1992). The Human Gastrointestinal Tract. In B.J.B Wood. (Ed). The Lactic Acid Bacteria, Vol. 1, London: Elsevier Science Publishers.

Nsofor, L. M., \& Osuji C. M. (1997). Stability, Rheology and Chemical Properties of Soymilk Concentrates Developed from Sprouted Soybeans. Journal of Food Science and Technology, 34,(1), 33-40.

Olutiola, P. O., Famurewa, O., \& Sonntag, H. G. (1991). An Introduction to General Microbiology: A Practical Approach. Germany: Heidelberg Publishers.

Omoni, A. O., \& Aluko, R. E. (2005). Soybean foods and their benefits: potential mechanisms of action. Nutrition Reviews, 63(8), 272-283. http://dx.doi.org/10.1111/j.1753-4887.2005.tb00141.x

Patidar, S. K., \& Prajapati, J. B. (1997). Methods for Assessing the Immunostimulating Properties of Dietary Lactobacilli - A critical Appraisal. Journal of Food Science and Technology, 34 (3), 181-194.

Poskitt, E. M. E. (1993). Infant: Feeding Problems. In the Encyclopedia of Food Science, Food Technology and Nutrition, Vol. 4, (pp 2014-2017). London: Academic Press.

Prescott, L. M., Harley, J. P., \& Klein, D. A. (1999). Microbiology 4th edition. Toronto: WCB/Mc Graw-Hill.

Rani, B., \& Kheterpaul, N. (1999). Probiotics fermentation of indigenously developed RSMT mixture: Effect of antinutrients and digestibility of starch and proteins. Journal of Food Science and Technology, 36 (1), 71 - 73.

Saarela, M., Mogensen, G., Matto, J., \& Matilda-Sandholm, T. (2000). Probiotic bacteria: safety, functional and technological properties. Journal of Biotechnology, $84, \quad 197 \quad-215$. http://dx.doi.org/10.1016/S0168-1656(00)00375-8

Samona, A. (1993). Soymilk. In the Encyclopedia of Food Science, Food Technology and Nutrition. Vol. 6, (pp 4239- 4242). London: Academic Press.

Scardovi, V. (1986). Genus Bifidobacterium Orla-Jesen. In R. E. Buchanan \& N. S. Gibbons (Ed.) (8 ${ }^{\text {th }}$ ed.) Sneath, Bergey's Manual of Determinative Bacteriology (pp. 669-676). Baltimore: Williams and Wilkins Pub.

Sgorbati, B., Biavati, B., \& Palenzona, D. (1995). The Genus Bifidobacterium, In: B.J.B. Wood \& W.H. Holzapfel, (Ed.), The Genera of Lactic Acid Bacteria, Vol 2, London: Blackie Academic and Professional Pub. http://dx.doi.org/10.1007/978-1-4615-5817-0_8

Tomasik, P. J., \& Tomasik P. (2003). Probiotics and Prebiotics. Journal of Cereal Chemistry, 80 (2), 113 - 117. http://dx.doi.org/10.1094/CCHEM.2003.80.2.113

Tsangalis, D., Ashton, J. F., McGill, A. E. J., \& Shah, N. P. (2002). Enzymic Transformation of Isoflavone Phytoestrogens in Soymilk by $\beta$-glucosidase - producing Bifidobacteria. Journal of Food Science, 67 (8), 3104-3113. http://dx.doi.org/10.1111/j.1365-2621.2002.tb08866.x

Villegas, R., Gao, Y. T., \& Yang, G. (2008). Legume and soy food intake and the incidence of type 2 diabetes in the Shanghai Women's Health Study. American Journal of Clinical Nutrition, 87(1), 162-167.

Visser, R., \& Holzapfel, W. H. (1992). Lactic Acid Bacteria in the Control of Plant Pathogens, In: B.J.B Wood. (Ed.). The Lactic Acid Bacteria Vol. 1. London: Elsevier Science Publishers.

Yusof, R. M., Haque, F., Ismail, M., \& Hassan, Z. (2000). Isolation of Bifidobacterium infantis and its antagonistic activity against ETEC 0157 and Salmonella typhimurium S-285 in weaning foods. Asia Pacific Journal of Clinical Nutrition, 9(2), 130-135. http://dx.doi.org/10.1046/j.1440-6047.2000.00154.x 
Table 1. Identification of human intestinal Bifidobacterium isolates

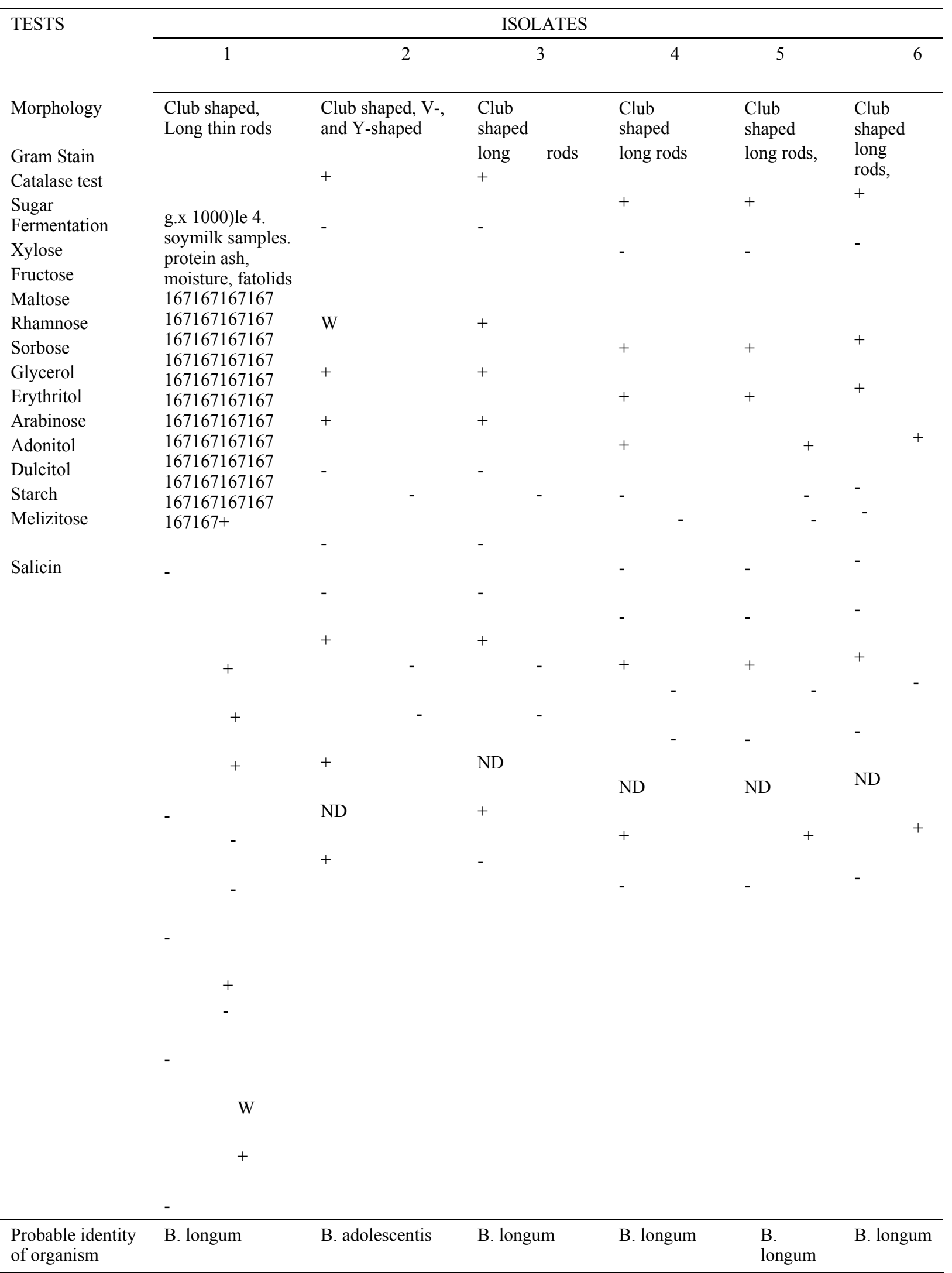

Symbol: $+=$ Positive, - = Negative, $\mathrm{W}=$ Weak, $\mathrm{ND}=$ Not determined 
Table 2. pH, TTA and Total solids of inoculated soymilk in storage (\%)

\begin{tabular}{|c|c|c|c|c|c|c|}
\hline \multirow{2}{*}{$\begin{array}{l}\text { Storage } \\
\text { Period } \\
\text { (Weeks) }\end{array}$} & \multicolumn{2}{|l|}{$\mathbf{p H}$} & \multicolumn{2}{|c|}{ TTA (\% Lactic acid)) } & \multicolumn{2}{|c|}{ Total Solids content (\%) } \\
\hline & $\begin{array}{l}\text { Ambient } \\
\text { Temp. }\end{array}$ & $\begin{array}{l}\text { Refrigerated } \\
\text { Temp. }\end{array}$ & $\begin{array}{l}\text { Ambient } \\
\text { Temp. }\end{array}$ & $\begin{array}{l}\text { Refrigerated } \\
\text { Temp. }\end{array}$ & $\begin{array}{l}\text { Ambient } \\
\text { Temp. }\end{array}$ & $\begin{array}{l}\text { Refrigerated } \\
\text { Temp. }\end{array}$ \\
\hline 0 & $5.72 \pm 0.12$ & $5.72 \pm 0.12$ & $0.17 \pm 0.02$ & $0.17 \pm 0.02$ & $5.16 \pm 0.21$ & $5.16 \pm 0.21$ \\
\hline 1 & $4.58 \pm 0.15$ & $5.63 \pm 0.13$ & $0.43 \pm 0.03$ & $0.19 \pm 0.01$ & $4.62 \pm 0.20$ & $4.78 \pm 0.19$ \\
\hline 2 & $4.51 \pm 0.18$ & $5.62 \pm 0.12$ & $0.45 \pm 0.02$ & $0.20 \pm 0.04$ & $4.26 \pm 0.22$ & $4.60 \pm 0.18$ \\
\hline 3 & $4.47 \pm 0.13$ & $5.64 \pm 0.14$ & $0.51 \pm 0.01$ & $0.21 \pm 0.01$ & $4.23 \pm 0.21$ & $4.57 \pm 0.22$ \\
\hline 4 & $4.39 \pm 0.12$ & $5.44 \pm 0.15$ & $0.46 \pm 0.04$ & $0.20 \pm 0.02$ & $4.53 \pm 0.19$ & $4.73 \pm 0.17$ \\
\hline 5 & $4.36 \pm 0.12$ & $5.44 \pm 0.19$ & $0.52 \pm 0.04$ & $0.18 \pm 0.01$ & $4.43 \pm 0.19$ & $4.50 \pm 0.09$ \\
\hline
\end{tabular}

Table 3. Amino Nitrogen, Crude protein and Carbohydrate contents of inoculated soymilk in storage

\begin{tabular}{|c|c|c|c|c|c|c|c|c|}
\hline \multirow[t]{2}{*}{$\begin{array}{l}\text { Storage } \\
\text { Period } \\
\text { (Weeks) }\end{array}$} & \multicolumn{2}{|c|}{ Amino Nitrogen (mg/ml) } & $\begin{array}{l}\text { Crude } \\
\text { Content } \\
(\%)\end{array}$ & Protein & \multicolumn{2}{|c|}{$\begin{array}{l}\text { Total Reducing Sugar } \\
\text { Content }(\mathrm{mg} / \mathrm{ml})\end{array}$} & $\begin{array}{l}\text { Carbohydrate } \\
\text { (\%) }\end{array}$ & Content \\
\hline & $\begin{array}{l}\text { Ambient } \\
\text { Temp. }\end{array}$ & $\begin{array}{l}\text { Refrig. } \\
\text { Temp. }\end{array}$ & $\begin{array}{l}\text { Ambient } \\
\text { Temp. }\end{array}$ & $\begin{array}{l}\text { Refrig. } \\
\text { Temp. }\end{array}$ & $\begin{array}{l}\text { Ambient } \\
\text { Temp. }\end{array}$ & $\begin{array}{l}\text { Refrig. } \\
\text { Temp. }\end{array}$ & $\begin{array}{l}\text { Ambient } \\
\text { Temp. }\end{array}$ & $\begin{array}{l}\text { Refrig. } \\
\text { Temp. }\end{array}$ \\
\hline 0 & $0.18 \pm 0.02$ & $0.18 \pm 0.02$ & $1.76 \pm 0.05$ & $1.76 \pm 0.5$ & $1.28 \pm 0.06$ & $1.28 \pm 0.06$ & $3.75 \pm 0.13$ & $3.75 \pm 0.13$ \\
\hline 1 & $0.22 \pm 0.01$ & $0.22 \pm 0.01$ & $1.84 \pm 0.11$ & $1.76 \pm 0.07$ & $3.77 \pm 0.19$ & $2.49 \pm 0.20$ & $1.67 \pm 0.09$ & $2.23 \pm 0.10$ \\
\hline 2 & $0.22 \pm 0.01$ & $0.22 \pm 0.02$ & $1.90 \pm 0.07$ & $1.77 \pm 0.11$ & $0.98 \pm 0.04$ & $1.78 \pm 0.03$ & $1.50 \pm 0.07$ & $1.91 \pm 0.06$ \\
\hline 3 & $0.22 \pm 0.02$ & $0.20 \pm 0.02$ & $1.95 \pm 0.02$ & $1.79 \pm 0.08$ & $0.98 \pm 0.02$ & $1.25 \pm 0.02$ & $1.43 \pm 0.10$ & $1.19 \pm 0.05$ \\
\hline 4 & $0.22 \pm 0.01$ & $0.20 \pm 0.03$ & $2.14 \pm 0.07$ & $2.08 \pm 0.04$ & $0.87 \pm 0.01$ & $1.09 \pm 0.05$ & $1.21 \pm 0.04$ & $1.19 \pm 0.06$ \\
\hline 5 & $0.22 \pm 0.02$ & $0.22 \pm 0.01$ & $2.14 \pm 0.09$ & $1.96 \pm 0.02$ & $0.75 \pm 0.02$ & $1.09 \pm 0.02$ & $1.21 \pm 0.06$ & $1.24 \pm 0.07$ \\
\hline
\end{tabular}




\section{Soybeans}

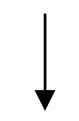

Cleaning (by hand picking)

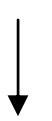

Boiling (For 20 mins. in 6 times its volume of boiling water)

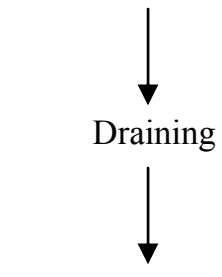

Grinding to paste

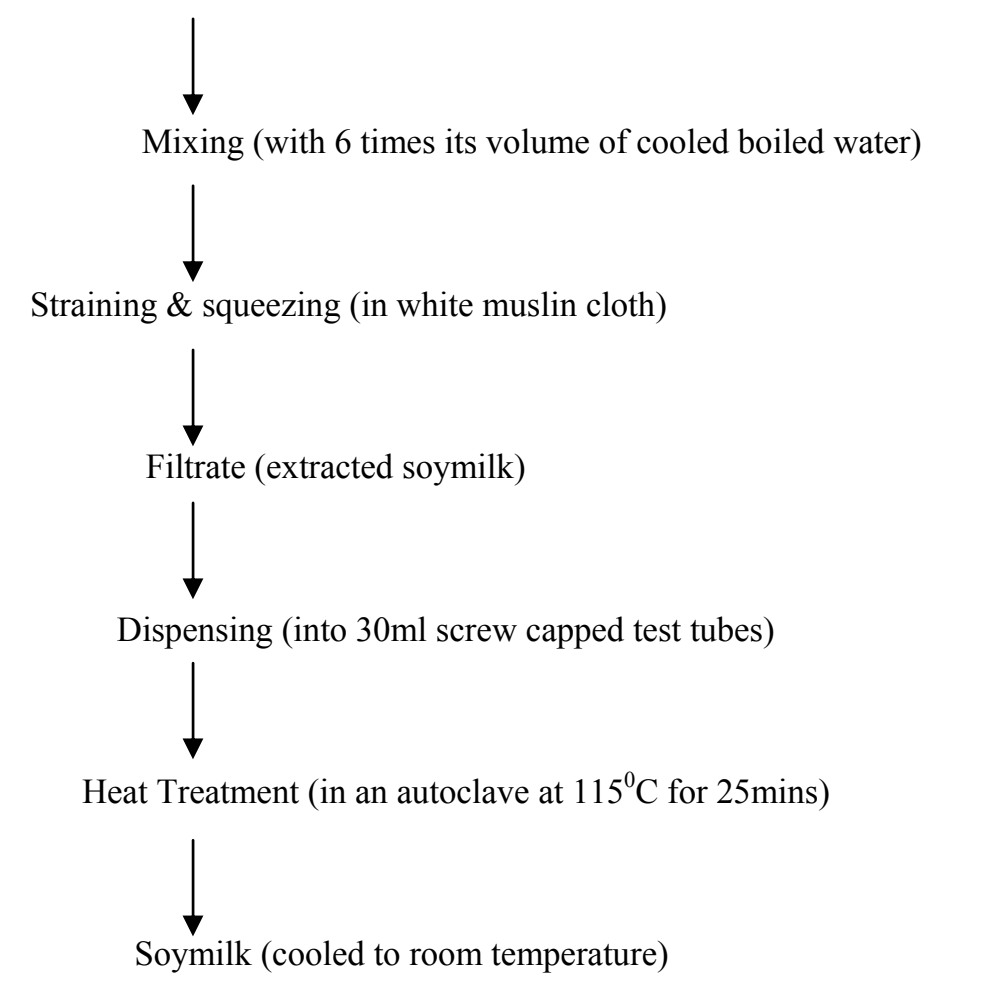

Figure 1. Flow chart for the preparation of soymilk (IITA, 1989) 


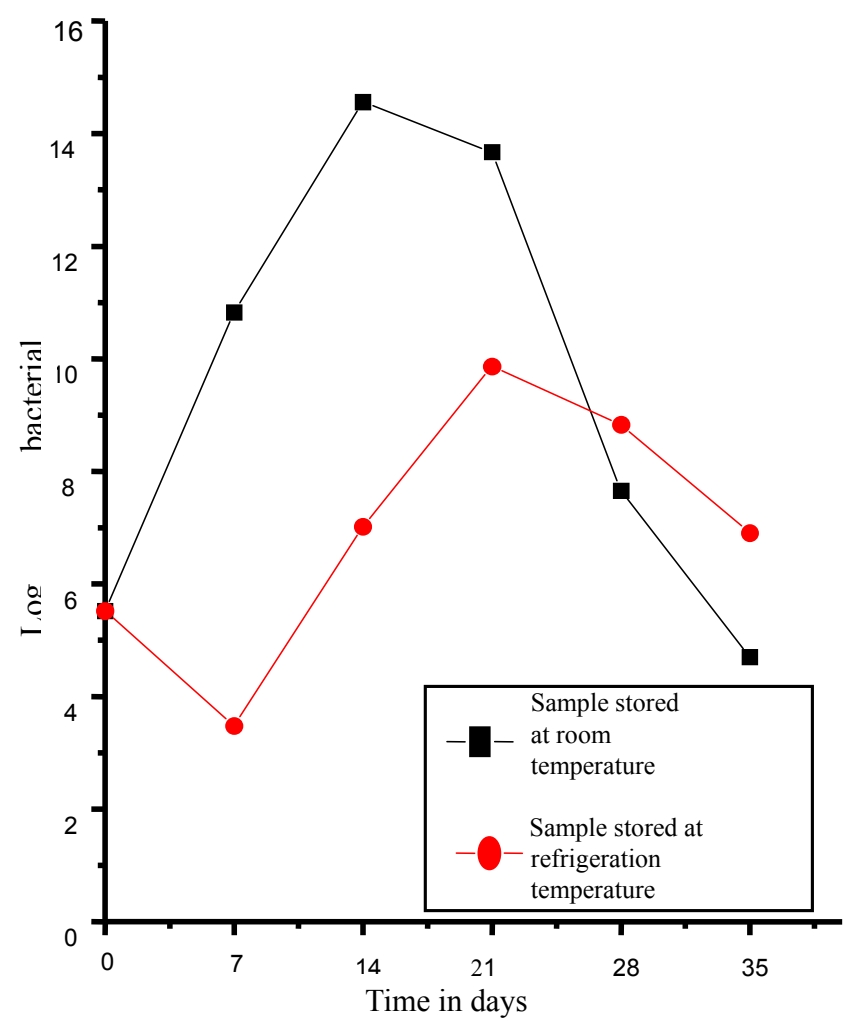

Figure 2. Viable count of B. longum in soymilk
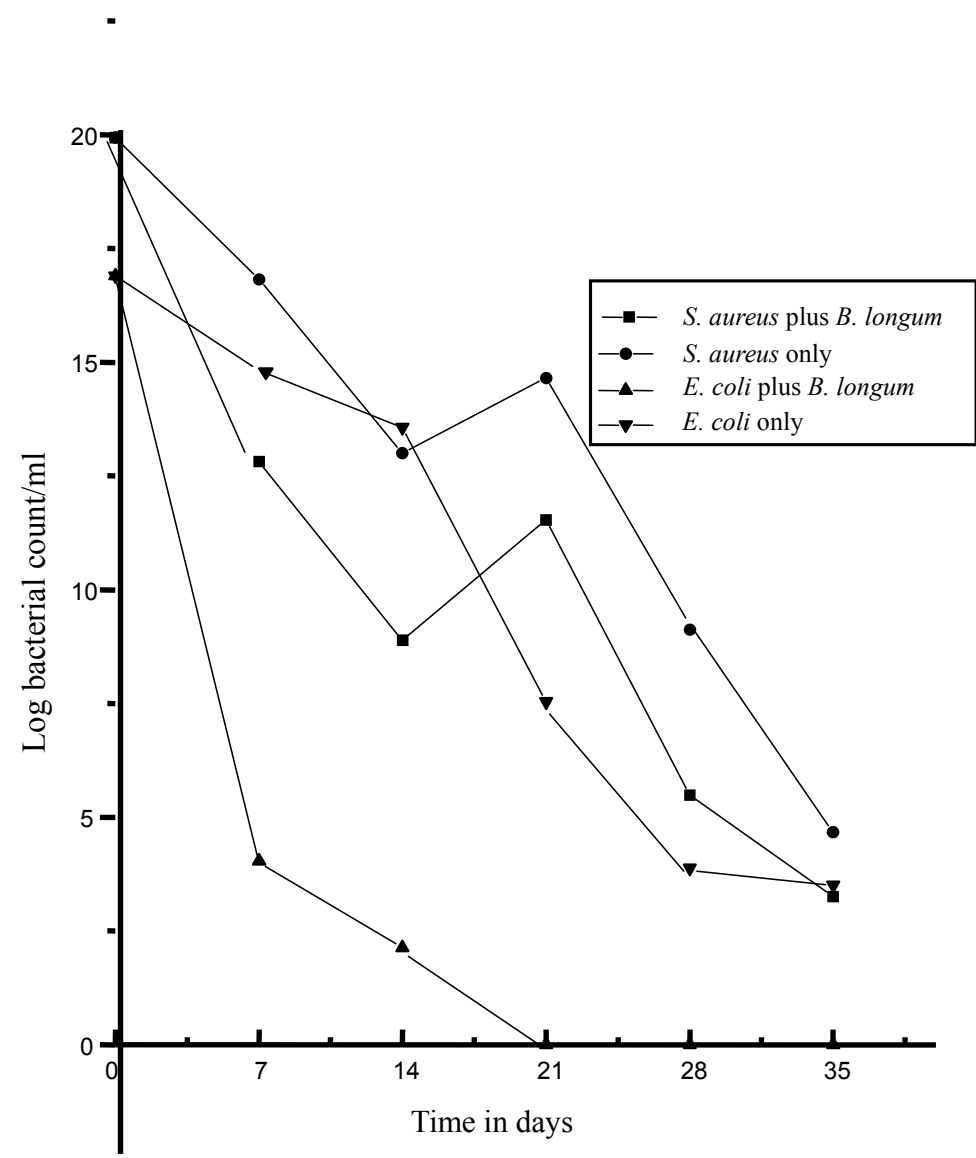

Figure 3. Antimicrobial effects of B. longum on Escherichia coli and Staphylococcus aureus in soymilk 